\title{
Comparison of the Antiinflammatory Activities of Three Medicinal Plants Known as "Meiduoluomi" in Tibetan Folk Medicine
}

\author{
Zhifeng ZHANG, ${ }^{a}$ Pei LUO, ${ }^{a}$ Jie LI, ${ }^{a}$ Tao YI,${ }^{b}$ \\ Jiangang WANG, ${ }^{a}$ Jing AN, ${ }^{a}$ and Hao ZHANG ${ }^{*, a}$ \\ ${ }^{a}$ West China School of Pharmacy, Sichuan University, No. 17, Section 3, Ren-Min-Nan-Lu Road, \\ Chengdu, Sichuan 610041, P. R. China, and ${ }^{b}$ Research and Development Division, School of \\ Chinese Medicine, Hong Kong Baptist University, Kowloon Tong, Kowloon, \\ Hong Kong Special Administrative Region, P. R. China
}

(Received October 9, 2007; Accepted January 7, 2008)

\begin{abstract}
Erigeron breviscapus (Vant.) Hand-mazz (EB), Erigeron multiradiatus (Lindl.) Benth (EM), and Aster brachytrichus Franch $(\mathrm{AB})$, confused under the vernacular name "meiduoluomi" by native people and traditional healers, have been used for the treatment of meningitis, polyneuritis, hepatitis, adenolymphitis, and enteronitis in traditional Tibetan medicine. In this study, the antiinflammatory activity of methanol extracts of all three plants was investigated in the xylene-induced ear edema model, carrageenan-induced paw edema model, and cotton pellet-induced granuloma model. It was found that the methanolic extracts of both EB and EM had strong inhibitory effects on the acute phase of inflammation in carrageenan-induced paw edema in rats. On the other hand, the methanolic extract of EM showed stronger effects than those of EB in xylene-induced ear edema. In the chronic test, the methanolic extracts of EB and EM resulted in a significant reduction in granuloma weight in rats. In addition, myeloperoxidase (MPO) activity was strongly reduced in the EB-treated and EM-treated groups, which indicated that EB and EM can inhibit certain inflammatory modulator factors that cause neutrophil aggregation in inflamed tissue, $e . g$., nuclear factor- $\kappa \mathrm{B}$. However, the methanolic extracts of AB had no antiinflammatory effects in the tested models and MPO assay. The similar effects of EM and EB in tested models provided some scientific basis for the traditional usage of meiduoluomi in inflammatory disease. However, the results also suggest that further study is needed to investigate the antiinflammatory profile of $A B$ and provide a scientific basis for the use of $\mathrm{AB}$ in inflammatory diseases.
\end{abstract}

Key words_-meiduoluomi; antiinflammatory activity; erigeron breviscapus; erigeron multiradiatus; aster brachytrichus

\section{INTRODUCTION}

It is very common in traditional folk medicine for different medicinal plants to share the same name due to the similarity of morphologic characteristics, personal and healer's experience, and traditional folk medicinal knowledge and practice. ${ }^{1,2)}$ "Meiduoluomi," which means "happy flowers" in Tibetan, is one example. Several plants from the Erigeron genus and Aster genus of the Compositae family have been widely used under the folk name meiduoluomi in traditional Tibetan medicine. In particular, Erigeron breviscapus (Vant.) Hand-mazz (EB), Erigeron multiradiatus (Lindl.) Benth (EM), and Aster brachytrichus Franch $(\mathrm{AB})$ are typical species with the name meiduoluomi. ${ }^{3,4}$ ) The three species are mainly distributed in the Himalayan region ${ }^{5)}$ and have been confused as meiduoluomi for a long time

\footnotetext{
*e-mail: zhanghhx@vip.sina.com
}

because it is difficult for native people and traditional healers to distinguish them when confronted with their similar morphologic feathers. ${ }^{6)}$

Meiduoluomi was noted for its heat-clearing and detoxicating effects and was used for the treatment of meningitis, polyneuritis, hepatitis, adenolymphitis, and enteronitis in traditional Tibetan medicine. ${ }^{3,4)}$ In previous studies, some chemical constitutes of meiduoluomi were isolated and identified, including scutellarin, erigeroside, quercetin, apeginin, pyromeconic acid, etc. ${ }^{7-12)}$

EB has commonly been used in preparations in official medicine in China, such as pills, capsules, and injections. ${ }^{13)}$ In recent years, pharmacologic studies have been conducted to confirm the reputed properties of EB and some results have also demonstrated its neuroprotective effects, ${ }^{14)}$ cardioprotective effects, ${ }^{15}$ ) anti-HIV-1 effects, ${ }^{16)}$ and regulatory and preventative effect on early liver injury. ${ }^{17,18)}$ However, no study has investigated the antiinflammatory activity of EB. 
Although EM and $\mathrm{AB}$ are also used as meiduoluomi along with EB in traditional Tibetan medicine, no studies on their pharmacologic activities have been reported to support their traditional folk medicine use. Therefore, we investigated and compared the in vivo and in vitro antiinflammatory activities of EB, $\mathrm{EM}$, and $\mathrm{AB}$, typical representatives of meiduoluomi, to verify the traditional medicinal use of the three species and confirm the safety of administration.

\section{MATERIALS AND METHODS}

Plant Materials The species were collected in their natural habitat at flowering and were authenticated by Professor Hao Zhang (Table 1). Voucher specimens (lot no. E12023 for EB, E12025 for EM, and $\mathrm{A} 06032$ for $\mathrm{AB}$ ) were deposited at the Herbarium Centre of the West China School of Pharmacy, Sichuan University, P. R. China.

Extraction The collected plants were dried under shade at room temperature and ground to powder. For extraction of the phytochemicals, about 200 $\mathrm{g}$ of powder of each sample was extracted with 2000 $\mathrm{ml}$ of methanol with boiling condition for $2 \mathrm{~h}$. This procedure was repeated at least three times until the extraction solvent became colorless. The obtained extracts were filtered over Whatman No. 1 filter paper, the filtrate was collected, and methanol was evaporated with a rotary evaporator at $45-50^{\circ} \mathrm{C}$ (to avoid any loss or degradation of plant constituents). The yields $(\%, w / w$ dry plant material) of dry extracts are presented in Table 1 . The dried extracts were suspended in $1 \%(\mathrm{w} / \mathrm{v})$ aqueous carboxy methylcellulose for administration to animals.

Animals Kunming mice weighing $18-22 \mathrm{~g}$ and standard Sprague-Dawley rats weighing 180-220 g were obtained from the Animal House, Pharmacy Discipline, Sichuan University, Chengdu. After being acclimated to the environment for 1 week, the

Table 1. Locality on the Studied Species and the Yields of the Crude Dry Methanol Extracts

\begin{tabular}{cllc}
\hline \hline Symbol & Plant species & Locality (altitude) & $\begin{array}{c}\text { Extract } \\
\text { yields } \\
(\%, \mathrm{w} / \mathrm{w})\end{array}$ \\
\hline $\mathrm{EB}$ & $\begin{array}{l}\text { Erigeron brevis- } \\
\text { capus }\end{array}$ & $\begin{array}{l}\text { Yuxi yunnan } \\
(2800 \mathrm{~m})\end{array}$ & 18.4 \\
$\mathrm{EM}$ & $\begin{array}{l}\text { Erigeron mul- } \\
\text { tiradiatus }\end{array}$ & $\begin{array}{l}\text { Luhuo, Sichuan } \\
(4250 \mathrm{~m})\end{array}$ & 20.3 \\
$\mathrm{AB}$ & $\begin{array}{l}\text { Aster } \\
\text { brachytrichus }\end{array}$ & $\begin{array}{l}\text { Kangding, Sichuan } \\
(3300 \mathrm{~m})\end{array}$ & 19.7 \\
\hline
\end{tabular}

animals were housed under environmentally controlled conditions at $25 \pm 1{ }^{\circ} \mathrm{C}$ with a 12 -h light/dark cycle. All animals had free access to standard rodent pellet food and water. The Animal Ethics Committees of the Faculty of Medicine, Sichuan University, approved all experimental protocols, in accordance with the "Principles of Laboratory Animal Care and Use in Research"' (Ministry of Health, Beijing, China).

Xylene-induced Ear Edema in Mice The effects of extracts on acute topical inflammation were evaluated using a modification of the methods of Atta and Alkohafi. ${ }^{19)}$ Male mice weighing 18-22 g were divided into eight groups of six animals each: the control group (distilled water-treated), positive group (indomethacin-treated), EB-treated groups, EMtreated groups, and AB-treated groups (low- and high-dose groups, respectively). All groups received the test agents orally for 5 consecutive days. Thirty minutes after treatment on day 5 , edema was induced in each mouse by applying $20 \mu \mathrm{l}$ of xylene to the inner and outer surfaces of the right ear. Fifteen minutes later, the animals were killed and 6-mm in diameter sections of the right and left ears were cut off and weighed. The edematous response was measured as the weight difference between the right and left ears. The antiinflammatory activity was expressed as the percentage of the inhibition of edema in treated mice in comparison with control mice.

Carrageenan-induced Paw Edema in Rats The experiment was carried out using the method of Winter et al. ${ }^{20)}$ Male rats weighing 180-220 g were divided into groups in the same way as in the xylene-induced mode and received the test agents orally for 5 consecutive days. One hour after the last treatment, paw edema was induced in the rats by injection of $0.1 \mathrm{ml}$ of carrageenan $(1 \% \mathrm{w} / \mathrm{v}$ in saline $)$ into the subcutaneous tissue of the right hindpaw. Paw edema volumes (EV) were determined at 1,3 , and $5 \mathrm{~h}$ using a volume displacement technique with a plethysmometer. Mean values of treated groups were compared with those of a control group and analyzed using statistical methods.

Cotton Pellet-induced Granuloma in Rats The effects of the three extracts on chronic inflammation was evaluated using the method of Winter and Porter. ${ }^{21)}$ Male rats weighing 180-220 g were divided into groups as above. On day 1 , the rats were anesthetized and $10 \mathrm{mg}$ of sterile cotton pellets were inserted in each axilla. Then all the groups were orally ad- 
ministered the test agents for 7 consecutive days. On the day 8 , the animals were anesthetized and the cotton pellets were removed surgically and freed from extraneous tissues. The pellets were dissected, weighed, then dried at $60^{\circ} \mathrm{C}$ for $18 \mathrm{~h}$, and weighed again after cooling. Increments in the dry weight of the pellets were calculated and taken as the measure of granuloma formation.

Myeloperoxidase Assay Tissue samples from the xylene-induced ear edema model were assessed biochemically with the neutrophil marker enzyme myeloperoxidase (MPO), using the method of Suzuki et al.22) All the ear tissue was homogenized in $\mathrm{K}_{2} \mathrm{HPO}_{4} /$ $\mathrm{KH}_{2} \mathrm{PO}_{4}$ buffer $50 \mathrm{mM}(\mathrm{pH} \mathrm{6})$ containing $0.5 \%$ hexadecyl trimethylammonium bromide using a Polytron (Ultra turrax x-25) homogenizer. After freeze-thawing three times, the samples were centrifuged at 2500 $\times \mathrm{g}$ for $30 \mathrm{~min}$ at $4^{\circ} \mathrm{C}$ and the resulting supernatant assayed spectrophotometrically for MPO. In brief, $40 \mu$ l of sample was mixed with $960 \mu$ l of phosphate buffer $50 \mathrm{mM}, \mathrm{pH} 6$, containing $0.167 \mathrm{mg} / \mathrm{ml}$ of $O$-dianisidine dihydrochloride and $0.0005 \%$ hydrogen peroxide. The change in absorbance at $460 \mathrm{~nm}$ was measured with a UV730 spectrophotometer (Shimadzu, Japan). MPO activity data are presented as units per milligram of tissue. One unit of MPO activity was defined as that degrading $1 \mu \mathrm{mol}$ of hydrogen peroxide per minute at $25^{\circ} \mathrm{C}$.

Statistical Analysis Results obtained from animal experiments are expressed as mean \pm S.E.M. and analyzed using Student's $t$-test. ${ }^{23)} \mathrm{A}$ difference between means of treated and control groups was considered significant at $p<0.05$.

\section{RESULTS}

Xylene-induced Ear Edema in Mice The activities of the methanol extracts of EB, EM, and $A B$ against xylene-induced ear edema are shown in Table 2. The methanol extract of EM caused a significant $(p<0.01)$ dose-related inhibition of the development of ear edema which paralleled the indomethacintreated group $(10 \mathrm{mg} / \mathrm{kg})$. Similarly, oral administration of the methanol extract of EB $(400 \mathrm{mg} / \mathrm{kg})$ also showed a significant effect $(p<0.05)$ against xylene-induced inflammation. On the contrary, the methanol extracts of $\mathrm{AB}$ did not show significant antiinflammatory effect in this model.

Carrageenan-induced Rat Paw Oedema The activities of the methanol extracts of EB, EM, and $\mathrm{AB}$ against carrageenin-induced paw edema are shown in Table 3. Both the methanol extracts of EM and EB (both $400 \mathrm{mg} / \mathrm{kg}$ ) administered orally showed significant dose-dependent inhibitory effects against edema formation 1,3 , and $5 \mathrm{~h}$ after carrageenan injection. The peak inhibitory effects of EM and EB $(75.38 \%$ and $69.23 \%$, respectively) were recorded with the dose of $400 \mathrm{mg} / \mathrm{kg}$ at $3 \mathrm{~h}(p<0.001)$, compared with indomethacin-treated group $(10 \mathrm{mg}$ / $\mathrm{kg}$ ). However, $\mathrm{AB}$ was ineffective in this test.

Cotton Pellet-induced Granuloma The results of the cotton pellet granuloma test are given in Table 4. The methanol extracts of EM and EB (both $400 \mathrm{mg}$ / $\mathrm{kg}$ ) showed similar effects on inhibition of the growth of granuloma tissue and caused a significant $(p<$ 0.001 ) nondose-related inhibition of granuloma formation, comparable to that of indomethacin $(10 \mathrm{mg} /$ $\mathrm{kg})$. However, the methanol extract of $\mathrm{AB}(400 \mathrm{mg} /$

Table 2. Effects of Methanol Extracts of EB, EM, and AB on Xylene-induced Ear Edema in Mice

\begin{tabular}{|c|c|c|c|c|c|}
\hline Groups & $\begin{array}{c}\text { Dose } \\
(\mathrm{mg} / \mathrm{kg})\end{array}$ & $\begin{array}{c}\text { Weight of right ear } \\
(\mathrm{mg})\end{array}$ & $\begin{array}{l}\text { Weight of left ear } \\
(\mathrm{mg})\end{array}$ & $\begin{array}{l}\text { Difference } \\
\quad(\mathrm{mg})\end{array}$ & $\begin{array}{l}\text { Inhibition } \\
(\%)\end{array}$ \\
\hline Control & - & $34.52 \pm 2.65$ & $16.81 \pm 2.44$ & $17.71 \pm 2.23$ & - \\
\hline Indomethacin & 10 & $26.52 \pm 2.47$ & $17.62 \pm 3.1$ & $8.90 \pm 2.85^{* *}$ & 49.75 \\
\hline \multirow{2}{*}{ EB } & 200 & $32.37 \pm 2.73$ & $17.25 \pm 1.42$ & $15.12 \pm 2.4$ & 14.62 \\
\hline & 400 & $30.45 \pm 1.68$ & $18.93 \pm 2.33$ & $11.52 \pm 2.7^{*}$ & 34.95 \\
\hline \multirow{2}{*}{ EM } & 200 & $29.56 \pm 2.64$ & $16.88 \pm 2.26$ & $12.68 \pm 2.5^{*}$ & 28.40 \\
\hline & 400 & $27.58 \pm 3.16$ & $18.34 \pm 3.37$ & $9.24 \pm 2.8^{* *}$ & 47.83 \\
\hline \multirow{2}{*}{$\mathrm{AB}$} & 200 & $32.72 \pm 2.55$ & $16.46 \pm 3.52$ & $16.26 \pm 2.8$ & 8.19 \\
\hline & 400 & $31.84 \pm 3.23$ & $16.73 \pm 1.13$ & $15.11 \pm 3.0$ & 14.68 \\
\hline
\end{tabular}

Each value represents the mean \pm S.E.M., $n=6$.

** $p<0.01$ compared with control, Student's $t$-test after analysis of variance.

* $p<0.05$ 
Table 3. Effects of Methanol Extracts of EB, EM, and AB on Carrageenan-induced Rat Paw Edema

\begin{tabular}{|c|c|c|c|c|c|c|c|}
\hline \multirow{3}{*}{ Groups } & \multirow{3}{*}{$\begin{array}{c}\text { Dose } \\
(\mathrm{mg} / \mathrm{kg})\end{array}$} & \multicolumn{6}{|c|}{ Time after carrageenan injection } \\
\hline & & \multicolumn{2}{|c|}{$1 \mathrm{~h}$} & \multicolumn{2}{|c|}{$3 \mathrm{~h}$} & \multicolumn{2}{|c|}{$5 \mathrm{~h}$} \\
\hline & & $\mathrm{EV}(\mathrm{ml})$ & EI $(\%)$ & $\mathrm{EV}(\mathrm{ml})$ & EI $(\%)$ & $\mathrm{EV}(\mathrm{ml})$ & EI $(\%)$ \\
\hline Control & - & $0.34 \pm 0.05$ & & $0.65 \pm 0.07$ & & $0.69 \pm 0.03$ & \\
\hline Indomethacin & 10 & $0.08 \pm 0.01^{* *}$ & 76.47 & $0.15 \pm 0.02^{* * *}$ & 76.92 & $0.18 \pm 0.03^{* * *}$ & 73.91 \\
\hline \multirow{2}{*}{ EB } & 200 & $0.33 \pm 0.04$ & 2.94 & $0.54 \pm 0.05$ & 16.92 & $0.58 \pm 0.04^{*}$ & 15.94 \\
\hline & 400 & $0.18 \pm 0.03^{*}$ & 47.06 & $0.20 \pm 0.03^{* * *}$ & 69.23 & $0.22 \pm 0.02^{* * *}$ & 68.12 \\
\hline \multirow{2}{*}{ EM } & 200 & $0.30 \pm 0.03$ & 11.76 & $0.58 \pm 0.07$ & 10.77 & $0.52 \pm 0.07^{*}$ & 24.64 \\
\hline & 400 & $0.10 \pm 0.02^{* *}$ & 70.59 & $0.16 \pm 0.02^{* * *}$ & 75.38 & $0.19 \pm 0.02^{* * *}$ & 72.46 \\
\hline \multirow{2}{*}{$\mathrm{AB}$} & 200 & $0.32 \pm 0.04$ & 5.88 & $0.68 \pm 0.05$ & -4.62 & $0.67 \pm 0.05$ & 2.90 \\
\hline & 400 & $0.33 \pm 0.06$ & 2.94 & $0.64 \pm 0.04$ & 1.54 & $0.68 \pm 0.02$ & 1.45 \\
\hline
\end{tabular}

Each value represents the mean \pm S.E.M., $n=6$. EV : edema volume ; EI : edema inhibition.

$* * * \quad p<0.001$.

** $p<0.01$ compared with control, Student's $t$-test after analysis of variance.

$* p<0.05$.

Table 4. Effects of Methanol Extracts of EB, EM, and AB on Cotton Pellet-induced Granuloma in Rats

\begin{tabular}{cccc}
\hline \hline Groups & $\begin{array}{c}\text { Dose } \\
(\mathrm{mg} / \mathrm{kg})\end{array}$ & $\begin{array}{c}\text { Weight of } \\
\text { granulation } \\
(\mathrm{mg})\end{array}$ & $\begin{array}{c}\text { Inhibition } \\
(\%)\end{array}$ \\
\hline control & - & $75.36 \pm 6.39$ & \\
Indomethacin & 10 & $47.25 \pm 7.04^{* *}$ & 37.30 \\
EB & 200 & $52.25 \pm 6.82^{* *}$ & 30.67 \\
& 400 & $50.34 \pm 7.12^{* *}$ & 33.20 \\
$\mathrm{EM}$ & 200 & $50.92 \pm 8.33^{* *}$ & 32.43 \\
& 400 & $51.26 \pm 5.68^{* *}$ & 31.98 \\
$\mathrm{AB}$ & 200 & $77.42 \pm 7.45$ & -2.73 \\
& 400 & $69.18 \pm 8.47$ & 8.20 \\
\hline
\end{tabular}

Each value represents the mean \pm S.E.M., $n=6$.

** $p<0.01$ compared with control, Student's $t$-test after analysis of variance.

Table 5. Effects of the Methanol Extracts of EB, EM, and $\mathrm{AB}$ on MPO Activity in the Mouse Ear Edema

\begin{tabular}{cccc}
\hline \hline Groups & $\begin{array}{c}\text { Dose } \\
(\mathrm{mg} / \mathrm{kg})\end{array}$ & $\begin{array}{c}\text { MPO } \\
(\mathrm{U} / \mathrm{mg} \text { of tissue })\end{array}$ & $\begin{array}{c}\text { Inhibition } \\
(\%)\end{array}$ \\
\hline control & - & $2.98 \pm 0.06$ & \\
Indomethacin & 10 & $1.02 \pm 0.28^{*}$ & 66 \\
$\mathrm{~EB}$ & 400 & $1.48 \pm 0.32^{*}$ & 50 \\
$\mathrm{EM}$ & 400 & $1.61 \pm 0.45^{*}$ & 46 \\
$\mathrm{AB}$ & 400 & $2.73 \pm 0.19$ & 8.4 \\
\hline
\end{tabular}

Each value represents the mean \pm S.E.M., $n=6$.

* $p<0.05$ compared with control, Student's $t$-test after analysis of variance.

$\mathrm{kg}$ ) showed no inhibitory effects on granuloma.

MPO Assay The percentages of inhibition of MPO activity in the inflamed tissues are shown in Table 5. MPO activity was inhibited significantly in the
EM-treated and EB-treated mice groups $(p<0.05)$, while AB did not show similar activity.

\section{DISCUSSION}

In the present study, the methanolic extracts of EB, $\mathrm{EM}$, and $\mathrm{AB}$ were examined in both acute and chronic inflammatory models. Xylene-induced ear edema and carrageenan-induced rat paw edema were adopted as acute inflammatory models, while cotton pelletinduced granuloma was used as a chronic model, since these three models have frequently been used to evaluate the antiinflammatory effects of natural products and have good predictive value for screening antiinflammatory agents. ${ }^{24,25)}$ The presence of edema was chosen as the prime sign of inflammation in the current study based on the literature. ${ }^{26)}$

Xylene-induced mouse ear edema in the present study led to fluid accumulation and edema characteristic of the acute inflammatory response in the in vivo model. The methanolic extract of EM showed stronger antiphlogistic effects against xylene-induced mouse ear edema than that of EB, while AB was ineffective in this model.

Carrageenan-induced paw inflammation has been accepted as a useful phlogistic tool for investigating systemic antiinflammatory agents. ${ }^{27)}$ Investigation of the effects on carrageenan-induced rat paw edema suggested that the methanolic extracts of EM and EB showed significant dose-dependent inhibitory activity against the acute inflammatory process over a period of $5 \mathrm{~h}$. Regarding the possible mechanisms involved, it was reported that carrageenan-induced acute inflammation may involve the synthesis and release of 
inflammatory mediators, such as leukotrienes, eseries, prostaglandins, histamine, bradykinins. ${ }^{28)}$ It is assumed that at least some of these mediators were subjected to significant inhibition by the methanol extracts of EM and EB. However, AB had no effects on the synthesis and release of inflammatory mediators.

Inflammation is a complex chronic process, which makes the study of it difficult. To investigate its extensive aspects, various test models have been developed. Among them, cotton pellet-induced granuloma formation is a typical feature of an established chronic inflammatory reaction and can serve as a subchronic and chronic inflammatory test model for the investigation of antiarthritic substances. ${ }^{29)}$ In chronic inflammatory states, the efficacy of antiinflammatory agents can be indicated by inhibiting the increase in fibroblasts and the infiltration of neutrophils and exudation. ${ }^{30)}$ The cotton pellet granuloma method is a suitable test for assessing the antiinflammatory activity drugs and widely used to evaluate the transudative and proliferative components of chronic inflammation. ${ }^{31)}$ Our results showed that the methanol extracts of EM and EB significantly inhibited the growth of granuloma tissue in a nondosedependent manner. On the contrary, AB showed little effect on reducing the weight of granuloma.

It is well known that the level of MPO activity is directly proportional to the neutrophil concentration in inflamed tissue, ${ }^{22}$ and thus measurement of MPO activity has been considered a quantitative and sensitive marker of chemotaxis and neutrophil infiltration in the inflammatory process. ${ }^{32)}$ Nuclear factor (NF) $-\kappa \mathrm{B}$ is an important and highly inducible transcriptional factor in the inflammatory response and induces subsequent neutrophil infiltration, and then leads to a variety of MPO activity. ${ }^{33,34)}$ In the present study, MPO activity was strongly reduced in the EBtreated group and EM-treated group but not in the AB-treated group, indicating that EB and EM inhibit certain inflammatory modulator factors that cause neutrophil aggregation in the inflamed tissue, e.g., $\mathrm{NF}-\kappa \mathrm{B}$. In contrast, $\mathrm{AB}$ did not show similar activity.

In our earlier study, it was found that flavonoids were the main constituents in EM and some individual ones (e.g., scutellarin, quercetin, apeginin, kaempferol) were isolated and identified. ${ }^{7,8)}$ Previous studies reported the presence of the following compounds in EB: scutellarin, erigeroside, quercetin, apeginin, pyromeconic acid, etc. ${ }^{9-12)}$ Considering the antiinflammatory activities of these flavonoids, ${ }^{35,36)}$ it was assumed that similar antiinflammatory effects of EM and EB in cotton pellet-induced granuloma and carrageenan-induced rat paw edema could be attributed to those similar flavonoids. On the other hand, the different inhibition rate of EM and EB in the xylene-induced mouse ear edema model may be caused by the different levels of flavonoids they contain. Moreover, their different constituents may be another reason. The absence of antiinflammatory activity of $A B$ suggests that the chemical constituents of $\mathrm{AB}$ may be significantly different from those of EM and EB. Therefore it is necessary to study further the detailed phytochemical constituents, compare the active components, and clarify their mechanisms of action.

\section{CONCLUSIONS}

In conclusion, the results of the present study provide scientific evidence supporting the application of EM and EB in inflammatory diseases. However, since $\mathrm{AB}$ was ineffective in the inflammation models used, further study is needed to investigate the antiinflammatory profile of $\mathrm{AB}$ and provide a scientific basis for its use in the treatment of inflammatory diseases.

Acknowledgements The authors thank the Bureau of Science and Technology of Sichuan province for the support for the applied fundamental study (Grant No. 2006Z08-081). Thanks are also due to the Ministry of National Education Doctoral Fund (No. 20020610089) for providing financial assistance.

\section{REFERENCES}

1) Vogel H., Gonzalez M., Faini F., Razmilic I., Rodrguez J., Martin J. S., Urbina F., J. Ethnopharmacol., 97, 97-100 (2005).

2) Speroni E., Govoni P., Guizzardi S., Renzulli C., Guerra M. C., J. Ethnopharmacol., 79, 265-272 (2002).

3) Dimaer D., Jingzhu Herbal, Science and Technology Press, Shanghai, 1986, p. 115.

4) Northwest Institute of Plateau Biology, China Academy of Science, "Record of Tibetan Medicine', Qinghai People's Press, Qinghai, 1991, p. 267.

5) Ling R., Chen Y. L., "Flora of China", Vol. 74, Science Press, Beijing, 1985, p. 299.

6) Gao L., Qi Y. F., Li X. F., Yunnan TCM Magazine, 25, 16-17 (2004). 
7) Zhang Y. J., Li L. Q., Yang P. Q., Zhang H., Acta Pharm. Sin., 33, 836-838 (1988).

8) Zhang Y. J., Li L. Q., Yang P. Q., Zhang H., Chin. Trad. Herbal Drugs, 29, 798-800 (1988).

9) Zhang R. W., Yang S. Y., Lin Y. Y., Acta Pharm. Sin., 16, 25-27 (1981).

10) Yue J. M., Lin Z. W., Wang D. Z., Sun H. D., Phytochemistry, 36, 717-718 (1994).

11) Yue J. M., Lin Z. W., Sun H. D., Chin. Chem. Lett., 8, 225-226 (1997).

12) Zhang W. D., Chen W. S., Wang Y. H., Liu W. Y., Kong D. Y., Li H. T., Chin. Mat. Med., 25, 536-538 (2000).

13) Chinese Pharmacopoeia Committee, "Chinese Pharmacopoeia," Vol. I, Chemical Industry Publishing House, Beijing, 2005, p. 100.

14) Liu H., Yang X. L., Tang R., Liu J., Xu H. B., Pharmacol. Res., 51, 205-210 (2005).

15) Zhang G. H., Wang Q., Chen J. J., Zhang X. M., Tam S. C., Zheng Y. T., Biochem. Biophys. Res. Commun., 334, 812-816 (2005).

16) Shi S. G., Shao S. Q., Chen K. N., Acta Academiae Medicinae Militaris Tertiae, 20, 320-322 (1998).

17) Shuai J., Dong W. W., Chin. Pharmaco. Bull., 14, 75-77 (1998).

18) Zhang Z., Sun M. C., Wang H. L., Le J., Wei Sheng Yan Jiu, 30, 86-88 (2001).

19) Atta A. H., Alkohafi A., J. Ethnopharmacol., 60, 117-124 (1998).

20) Winter C. A., Risley E. A., Nuss G. W., Proc. Soc. Exp. Biol. Med., 111, 544-547 (1962).

21) Winter C. A., Porter C. C., J. Am. Pharm. Assoc., 46, 515-519 (1957).

22) Suzuki K., Ota H., Sasagawa T. S., Fujikura T., Ann. Biochem., 132, 345-351 (1983).
23) Woodson S. A., Crothers D. M., Biochemistry, 26, 904-912 (1987).

24) Jia J. M., Wu C. F., Liu W., Yu H., Hao Y., Zheng J. H., Ji Y. R., Biol. Pharm. Bull., 28, 1612-1614 (2005).

25) Mujumdar A. M., Misar A. V., J. Ethnopharmacol., 90, 11-15 (2004).

26) Sur T. K., Pandit S., Battacharyya D., Kunar C. K., Lakshmi S. M., Chattopadhyay D., Mandal S. C., Phytother. Res., 16, 669-671 (2002).

27) Badilla B., Arias A. Y., Arias M., Mora G. A., Poveda L. J., Fitoterapia, 74, 45-51 (2003).

28） Di R. M., Giroud J. P., Willoughby D. A., J. Pathol., 104, 15-29 (1971).

29) Spector W. G., Int. Rev. Exp. Pathol., 8, 1-55 (1969).

30) Swingle K. F., Shideman F. E., J. Pharmacol. Exp. Ther., 183, 226-234 (1972).

31) Gupta M., Mazumdar U. K., Sivakumar T., Vamsi M. L., Karki S. S., Sambathkumar R., Manikandan L., Biol. Pharm. Bull., 26, 13421344 (2003).

32) Smith J. A., J. Leukoc. Biol., 56, 672-686 (1994).

33) Campos M. M., de Souza G. E., Ricci N. D., Resquero J. L., Teixeira M. M., Calixto J. B., Br. J. Pharmacol., 135, 1107-1114 (2002).

34) Goulart S., Moritz M. I., Lang K. L., Liz R., Schenkel E. P., Frode T. S., J. Ethnopharmacol., 113, 346-353 (2007).

35) Parveen Z., Deng Y., Saeed M. K., Dai R., Ahamad W., Yu Y. H., Yakugaku Zasshi, 127, 1275-1279 (2007).

36) Clavin M., Gorzalczany S., Macho A., Munoz E., Ferraro G., Acevedo C., Martino V., J. Ethnopharmacol., 112, 585-589 (2007). 